ESJ Natural/Life/Medical Sciences

\title{
Trends in the Collaboration Pattern of Moroccan Research in Earth Sciences from 1984 to 2019: A Case Study
}

\author{
Fida Medina, PhD
}

Former Professor at the Institut Scientifique (University Mohamed V in Rabat) Moroccan Association of Geosciences, Rabat, Morocco

Doi:10.19044/esj.2021.v17n14p183

Submitted: 11 February 2021

Accepted: 19 March 2021

Published: 30 April 2021
Copyright 2021 Author(s)

Under Creative Commons BY-NC-ND

4.0 OPEN ACCESS

Cite As:

Medina F. (2021). Trends in the Collaboration Pattern of Moroccan Research in Earth Sciences from 1984 to 2019: A Case Study. European Scientific Journal, ESJ, 17(14), 183. https://doi.org/10.19044/esj.2021.v17n14p183

\begin{abstract}
The output of the Moroccan researchers in Earth sciences and their collaboration trends were studied for the period 1984-2019 using the example of the Journal of African Earth Sciences, the preferred journal of this community, and by using simple bibliometric indicators such as collaboration rate and collaboration level. The main results of the study are: (1) Moroccan researchers participated in 253 articles among which, only 12 were singleauthor papers. Multi-authorship is the rule with a mode of 4 authors per paper for 45 articles; (2) the number of authors reached 1251 in all papers. When only international collaboration is considered, 1051 authors are found, from which about $48 \%$ are from Morocco and 52\% belong to other 31 countries; (3) International collaboration, which was exclusively with French researchers and institutions until the 1990s, grew in number but declined in share to 33$42 \%$ in the last 15 years, while collaboration with other countries became more important because of the internationalization of research programs.
\end{abstract}

Keywords: Earth sciences, research evaluation, bibliometry, research collaboration

\section{Introduction}

During the last decades, globalization of scientific research has led to the increase of multi-disciplinary international collaboration, which has 
become indispensable especially in fields which require more or less high technology (Hagedoorn et al., 2000; Zitt \& Bassecoulard, 2004). Consequently, peer-reviewed publications, which are the main outcome of research projects, are nowadays mostly co-authored by numerous scientists belonging to national and international scientific networks (Glänzel \& Schubert, 2004). In extreme cases, the number of co-authors may attain more than 3,000 as in the mega-technological projects (e.g., CERN: European Organization for Nuclear Research). Generally and comparatively to surveys (Laudel, 2002), co-authorship of papers is considered to be a good indicator of collaborative activity. Nevertheless, it can be criticized because of being partial (many collaborators are not included in the authors' list) and because of the undefined degree of participation of each co-author in the various tasks, such as project and manuscript preparation and experimental tasks (Katz \& Martin, 1997).

From the analysis of more than 17 million publications listed in ISI Web of Science (WoS) for the period 1981-2005, Van Leeuwen (2005) stated that those produced by collaboration increased from $30 \%$ of total publications in 1981 to almost $70 \%$ in 2005 . Thus, the internationalization of research led to the decrease of single-address articles in all fields (including social sciences and humanities) from $70 \%$ in 1981 to $43 \%$ in 2005 , although the rate is quite variable from one field to another. Leydersdorff and Wagner (2008) also observed from the analysis of more than 1 million documents listed in the SCI that the number of internationally co-authored documents increased linearly from $10.1 \%$ of total records in 1990 to $23.2 \%$ in 2005 , while the number of addresses to these records grew exponentially from 147,411 in 1990 to 618,928 in 2005. They stated that the break-up of the former Soviet Union and Yugoslavia into the present-day countries should be taken into account.

In the case of Morocco, a developing country whose research and higher education are inherited from the French educational system (Medina, 2015), individual, national and international collaboration between Moroccan doctorate students and their foreign French supervisors have always existed since independence. Formal collaboration between Moroccan universities and foreign institutions did not start before the late 1970s and early 1980s with the Franco-Moroccan "Action Intégrées" projects. Hence, this is followed by several cooperation agreements with Belgium (1994), Spain (1996), Portugal (1999), and Italy (2005) (DESFCRS, 2006). More recently, several international (mainly peri-Mediterranean) projects developed new networks and therefore have extended their collaboration to Moroccan institutions in numerous fields such as botany (e.g., Tela Botanica), geodynamics (e.g., PICASSO, TOPO-IBERIA), and natural hazards (WM in seismology, IOC/ICG/NEAMTWS for tsunami warning). 
However, little is known quantitatively about the joint output of Moroccan researchers and their partners. The CNRST stated that up to $80 \%$ of the 1075 projects managed were with French institutions (DESFCRS 2006), whereas the report on Moroccan research evaluation indicated that $65 \%$ of the co-authored papers in the ISI database from 1991 to 1999 were with French researchers (Kleiche-Dray, 2007; Waast \& Kleiche-Dray, 2009). These data are concerned with a given period and do not or briefly refer to the temporal evolution in collaboration, a fact that can be eye-witnessed from the nationalities of researchers attending meetings and/or when visiting teams are received by Moroccan universities.

In order to contribute to the knowledge on the collaborative research undertaken by the Moroccan laboratories, this paper focuses on exposing the results of a bibliometric study on the present-day size and evolution of collaboration with foreign institutions. This was done using the number of papers and affiliation of co-authors in a Scopus-indexed journal, the Journal of African Earth Sciences, because Earth sciences are recognized as a highly collaborative field (e.g., Franceschet \& Costantini, 2010; Abramo et al., 2013).

In the case of Morocco, collaboration in Earth sciences has become necessary because of several factors: (1) The lack of analytical facilities in the country leads local laboratories to establish collaborations in order to accomplish the analytical part of projects, although the CNRST created in 2006 an analysis centre (the UATRS), which does not cover all Earth science domains and is subject to slow bureaucracy; (2) Geoscientists from several countries are interested in studying the common geological history of Morocco with North America, Iberia, and Africa; (3) Some neighboring countries (Portugal and Spain in particular) proposed establishing formal collaborations for assessing common geo-hazards such as earthquakes and tsunamis; and (4) Several governmental projects such as the trans-Gibraltar Straits fixed connection, the PNCG (National Plan for Geological Cartography), and petroleum exploration were launched by means of international competitive biddings which attracted foreign universities, companies, and collaborating nationals (ONHYM and universities). The publication output is considered to intimately reflect the Moroccan research as previously estimated by Waast and Kleiche-Dray (2009) in their research evaluation report on Morocco. Nonetheless, several constraints were highlighted by Bouabid and Martin (2009) and Medina (2015).

\section{Database and Method}

\subsection{Brief History}

In Morocco, work in geoscience was first published in Bulletin and Mémoires de la Société des Sciences Naturelles et Physiques du Maroc (19211975), in Notes et Mémoires du Service géologique du Maroc (1927-present) 
and in the journal Mines, Géologie et Energie (1958-1998). The geophysical studies were also published from 1934 to 1956 in the Annales du Service de Physique du Globe du Maroc until the Independence of Morocco. In 1975, the Bulletin de la Société des Sciences was replaced by the Bulletin de l'Institut Scientifique, a multidisciplinary series from 1976 to 2000, which became specialized in 2001. Many attempts to create journals were made, but they were ephemeral usually for financial and marketing reasons (sales). Among others were the Bulletin de la Faculté des Sciences de Marrakech (1980s), the Bulletin des Sciences de la Terre (Rabat) (early 1980s), and the Cahiers de la Recherche Scientifique (Casablanca) in the 2000s. Outside the country, Moroccan researchers usually publish in French journals such as the Bulletin de la Société Géologique, Comptes-Rendus de l'Académie des Sciences, Sciences Géologiques, Géologie Méditerranéenne, and Annales de la Société Géologique du Nord. There are still no published statistics on the number of publications and researchers involved.

The publication of the universities' rankings in the 2000s had several effects on the scientific publication, among which is the shift to English language and the disappearance of several journals that suffered from the lack of submissions (case of Géologie Méditerranéenne, highly coveted by Moroccan researchers). At present, Moroccan researchers publish in a large number of journals ranging from Nature to national journals, depending on the administrative requirements for promotion, which are generally two papers at least in Scopus-indexed journals.

\subsection{Journal Choice and Characteristics}

In order to study the main trends in research collaboration, articles published by Moroccan geoscientists in the Journal of African Earth Sciences (and the Middle East from 1988 to 1993), abbreviated to JAES in the following, were used because of several parameters: (1) The journal is multidisciplinary. As a result, it is possible to find numerous fields and then more articles of Moroccan researchers than in specialized journals; (2) It is the journal preferred by the Moroccan researchers in Earth sciences, and the tribune of the Geological Society of Africa; (3) It publishes papers in highlycollaborative fields, such as petrology and geochemistry.

The journal's impact factor for 2020 was 1.6. The number of volumes per year is 12 since 2012, after being 3 from 2004 to 2011 and 2 from 1994 to 2003. Each volume comprised 4-5 issues until 2012 before decreasing to 1 issue per volume.

Before exposing the results, it should be reasonable to assess how much the JAES reflects the general tendency of Moroccan researchers in Earth sciences. To this purpose, the output of Moroccan geoscientists in JAES for the time window 1996-2019 was plotted with that of all Earth science papers 
on Morocco published in SCImago database (Figure 1), which is based on Scopus indexed journals. The percentage of papers in JAES varied from 3\% (recent years) to $30 \%(2001,2004)$ of all Earth sciences' papers on Morocco in SCImago. A remarkable feature is the parallel variations observed until 2006 (Figure 1), which is emphasized by well-matching maxima and minima. Thus, this undoubtedly indicates that the whole SCImago output in Moroccan ES was influenced by that published in the JAES. The subsequent decline after 2006 may be related to the fact that after the publication of the global university rankings, new international teams preferred to publish their results in more specialized journals with higher impact factors than JAES, such as Precambrian Research (IF=5.6 in 2014), Tectonophysics ( $\mathrm{IF}=2.8$ in 2014), and Marine Geology (IF=2.7 in 2014).

Author names and affiliations were picked up through ScienceDirect website using keywords « Morocco » or « Maroc». Affiliation of authors was carefully checked for each article because in some cases, it was found that the same authors had a foreign laboratory address when they were students and a national one when they started working in Morocco. When the authors had a double address, only the first one was considered. The few non-Moroccan authors (coopérants) were also considered when they were working in Moroccan universities and companies. Finally, the papers co-authored by Moroccan researchers on the geology of foreign countries were not taken into account because of their few numbers. Some affiliations were grouped when the companies changed their names or had subsidiaries. This is the case of Managem and ONA holding, ONAREP and BRPM which changed to ONHYM-PH and ONHYM-PM respectively. In addition, professor training institutions (ENS, CRMEF) were grouped. This cannot be done through automatic pick-up.

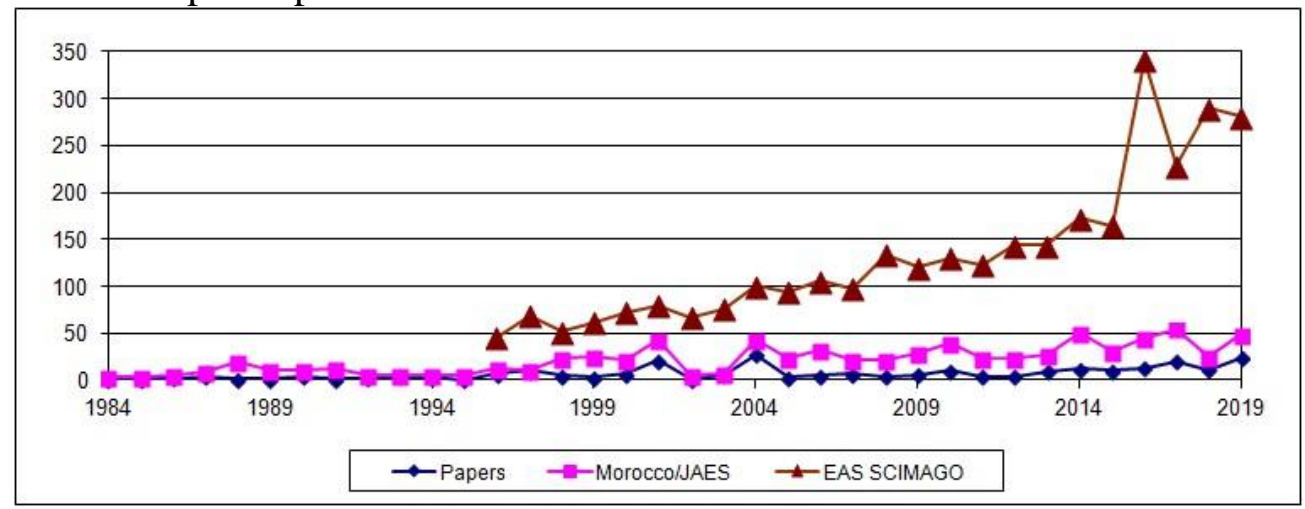

Figure 1. Number of papers published by Moroccan authors in the JAES from 1984 to 2019 by year (lower graph) compared to the papers of the Journal of African Earth Sciences including the keyword "Morocco/Maroc" in the Sciencedirect search engine (middle graph) and to the SCImago papers on Moroccan output in geosciences (upper graph) 


\section{Results}

\subsection{Moroccan Researchers' Output}

Sciencedirect search engine for JAES provided 789 papers and bibliographic notes quoting the word "Morocco" and "Maroc" for the period 1984-2019. Here, the total number of papers authored by at least one researcher from Morocco was 253. This corresponds to a mean percentage of $32 \%$, but ranges from 0\% (1995) to 91\% (1997) as shown in Figure 2.

Consequently, the general yearly output (i.e., number of published articles) was quite irregular, ranging from 0 to 27 papers (Figure 1). The number of articles per year was gathered in 5-year windows (6 years for the relatively scarce first interval) for better visualizing on the temporal evolution of the output. Figure 3 shows that for this window, the number of papers increased from 11 during 1984-1989 to 77 during 2015-2019 (Figure 3 and Table 1). The large peak with 62 papers that can be observed during the interval 2000-2004 is related to the publication of two special issues on Morocco in 2001 and 2004.

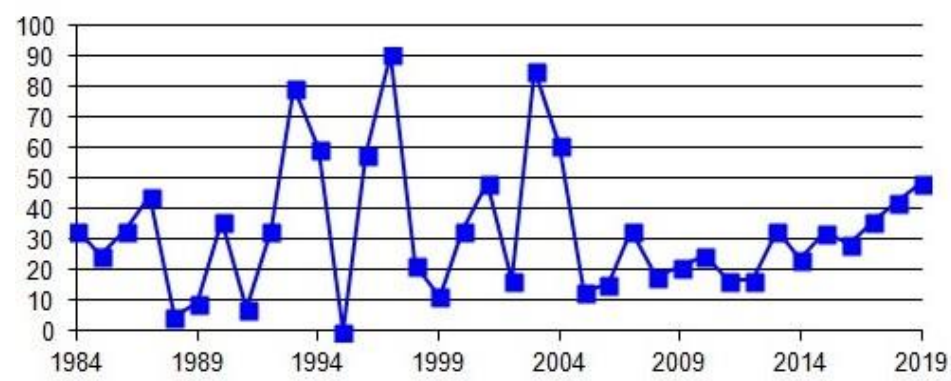

Figure 2. Percentage of publications of Moroccan authors with respect to the papers of the Journal of African Earth Sciences including the keyword "Morocco/Maroc" in the

Sciencedirect search engine

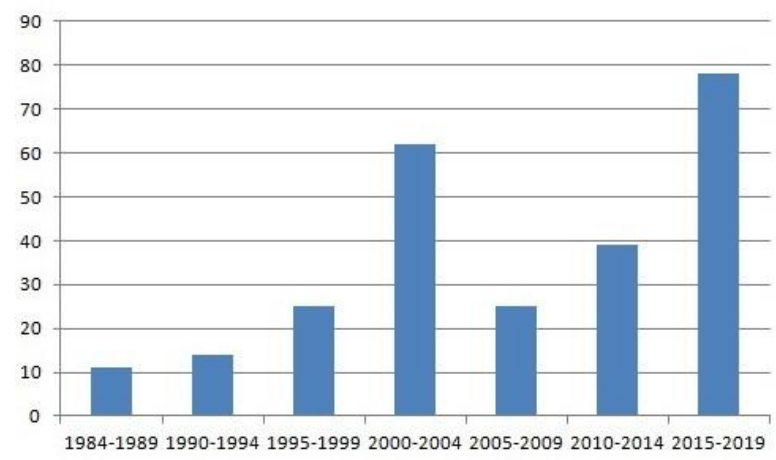

Figure 3. Number of papers of Moroccan authors published from 1984 to 2019 in the JAES by 5 year intervals ( 6 years for the first one) 
Table 1. Number of papers by Moroccan authors, authors, and authors per paper in the JAES by 5 year intervals (6 years for the first one) from 1984 to 2019

\begin{tabular}{cccc}
\hline Period & Authors & Articles & Authors/Paper \\
\hline $1984-1989$ & 24 & 11 & 2.18 \\
\hline $1990-1994$ & 45 & 14 & 3.21 \\
\hline $1995-1999$ & 87 & 25 & 3.48 \\
\hline $2000-2004$ & 262 & 62 & 4.22 \\
\hline $2005-2009$ & 112 & 25 & 4.48 \\
\hline $2010-2014$ & 248 & 39 & 6.26 \\
\hline $2015-2019$ & 473 & 77 & 6.14 \\
\hline Total & $\mathbf{1 2 5 1}$ & $\mathbf{2 5 3}$ & $\mathbf{4 . 9 5}$ \\
\hline
\end{tabular}

By first appearance among all co-authors by paper, Moroccan researchers occupied the first rank in 127 papers from 190 internationally coauthored papers $(66.8 \%)$.

\subsection{Number of Authors}

Taking into account that repetition of names was allowed, the total number of authors of the 253 papers is 1251, of which 703 were Moroccan. Single-author papers were only 12, which imply a Collaborative Rate (CR) rate of papers with more than one author; Franceschet and Costantini (2010) of 0.99. The mean number of authors per paper for the period 1984-2019 (or Collaborative Level CL sensu Franceschet \& Costantini, 2010) is 5. The mode is 4 authors by paper (45 papers) (Figure 4 and Table 1), followed by 3 and 5 authors (37 papers each), and the highest number of co-authors (maxCL; Levitt \& Thelwall, 2009) is 19.

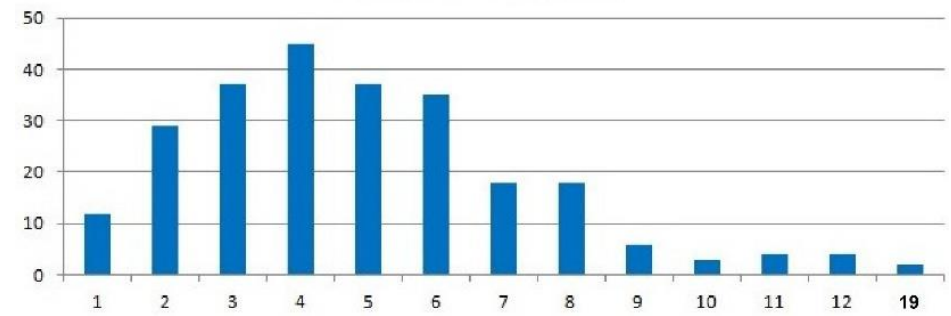

Figure 4. Number of co-authors by paper for the whole output of Moroccan authors in the JAES from 1984 to 2019 


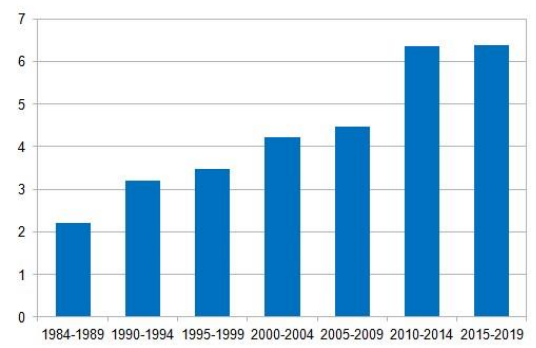

Figure 5. Evolution of the mean number of co-authors per paper by 5-year periods for articles co-authored by Moroccan Researchers in the JAES

When the partial mean is calculated for 5-year intervals, it appears that the number of authors per paper has regularly increased from 2.1 during 19841989 to 6 during 2010-2019 (Table 1 and Figure 5).

By detailed affiliation to Moroccan laboratories, the largest number of papers (67) were published by 115 co-authors (repetition of names allowed) from the Faculty of Sciences of Marrakech. This is followed by those of the faculties of sciences of El Jadida (42 papers by 93 researchers), Rabat (33 papers by 43 researchers), and the Faculty of Sciences and Techniques of Marrakech ( 32 papers by 54 researchers). The other institutions contributing with 13 papers or more are listed in Table 2.

Table 2. Number of articles published by Moroccan authors in the JAES (upper part and number of authors (lower part) by institution) from 1984 to 2019. FS= Faculty of Science;

FST = Faculty of Sciences and Techniques; $M=$ Marrakech; R=Rabat; EJ=El Jadida;

$\mathrm{O}=$ Oujda; A=Agadir; Mk=Meknès; F=Fès; ISR= Institut Scientifique of Rabat; MEM=Ministry of Energy and Mines

\begin{tabular}{cccccccccc}
\hline \multirow{2}{*}{ Institution } & Papers (P) & $1984-$ & $1990-$ & $1995-$ & $2000-$ & $2005-$ & $2010-$ & $2015-$ & \multirow{2}{*}{ Total } \\
& Authors (A) & 1989 & 1994 & 1999 & 2004 & 2009 & 2014 & 2019 & \\
\hline \multirow{2}{*}{ FSM } & $\mathrm{P}$ & 0 & 1 & 9 & 20 & 6 & 7 & 24 & $\mathbf{6 7}$ \\
& $\mathrm{A}$ & 0 & 2 & 17 & 31 & 6 & 15 & 44 & $\mathbf{1 1 5}$ \\
\hline \multirow{2}{*}{ FSEJ } & $\mathrm{P}$ & 0 & 1 & 2 & 15 & 6 & 6 & 12 & $\mathbf{4 2}$ \\
& $\mathrm{A}$ & 0 & 1 & 2 & 34 & 8 & 13 & 35 & $\mathbf{9 3}$ \\
\hline \multirow{2}{*}{ FSR } & $\mathrm{P}$ & 3 & 5 & 4 & 11 & 4 & 3 & 3 & $\mathbf{3 3}$ \\
& $\mathrm{A}$ & 3 & 5 & 5 & 18 & 4 & 5 & 3 & $\mathbf{4 3}$ \\
\hline \multirow{2}{*}{ FSTM } & $\mathrm{P}$ & 0 & 1 & 1 & 7 & 5 & 9 & 9 & $\mathbf{3 2}$ \\
& $\mathrm{A}$ & 0 & 1 & 1 & 13 & 6 & 16 & 17 & $\mathbf{5 4}$ \\
\hline \multirow{2}{*}{ FSA } & $\mathrm{P}$ & 0 & 0 & 2 & 10 & 3 & 2 & 9 & $\mathbf{2 6}$ \\
& $\mathrm{A}$ & 0 & 0 & 4 & 23 & 6 & 2 & 17 & $\mathbf{5 2}$ \\
\hline \multirow{2}{*}{ FSO } & $\mathrm{P}$ & 0 & 3 & 2 & 5 & 2 & 7 & 6 & $\mathbf{2 5}$ \\
& $\mathrm{A}$ & 0 & 3 & 3 & 8 & 2 & 15 & 7 & $\mathbf{3 8}$ \\
\hline \multirow{2}{*}{ ISR } & $\mathrm{P}$ & 3 & 3 & 2 & 3 & 1 & 7 & 4 & $\mathbf{2 3}$ \\
& $\mathrm{A}$ & 3 & 4 & 2 & 3 & 1 & 8 & 10 & $\mathbf{3 1}$ \\
\hline \multirow{2}{*}{ MEM } & $\mathrm{P}$ & 3 & 1 & 2 & 1 & 0 & 2 & 8 & $\mathbf{1 7}$ \\
& $\mathrm{A}$ & 3 & 1 & 2 & 1 & 0 & 3 & 9 & $\mathbf{1 9}$ \\
\hline \multirow{2}{*}{ F } & & & & & & & & &
\end{tabular}


FSMk

\begin{tabular}{lllllllll}
\hline $\mathrm{P}$ & 0 & 0 & 4 & 4 & 0 & 4 & 4 & $\mathbf{1 6}$ \\
$\mathrm{A}$ & 0 & 0 & 6 & 9 & 0 & 9 & 4 & $\mathbf{2 8}$ \\
\hline
\end{tabular}

\subsection{Collaboration Indicators}

Several types of collaboration are discussed below:

1. Intra muros or internal collaboration between members of the same research unit, which is reflected by a single address affiliation in the papers.

2. Domestic (national) collaboration involving two or more research units belonging to one or more Moroccan universities, companies, and administrations. Domestic collaboration was also considered to exist between Moroccan institutions even when the paper was co-authored with foreign researchers.

3. International collaboration involving at least one researcher from a foreign research unit. This type of collaboration may be symmetric (a close number of national and foreign co-authors) or asymmetric (a large number of co-authors on one side).

\section{Domestic Collaboration}

Single-address articles were 17 out of 253 (6.7\% of total output), with the number of co-authors per paper ranging from 2 to 5 . Researchers of the Faculty of Sciences of Marrakech published 4 papers, followed by those of the faculties of Agadir, El Jadida, and the Faculty of Sciences \& Techniques of Marrakech (2 papers).

In the bi- to multi-institutional case, only 34 articles from 253 (13.4\%) were found for pure domestic collaboration, while those involving domestic collaboration and foreign researchers attained 81 papers. The highest frequency was observed for 2 co-authors belonging to 2 institutions (32 papers), followed by $2+1$ (23 papers) and $3+1$ co-authors (11 papers).

In the case of 3 institutions or more, 9 among the 35 papers have $2+1+1$ co-authors and 7 have $1+1+1$ co-authors. 
Table 3. Overall domestic collaboration papers of Moroccan geoscientists in JAES articles, including single address and multi-addresses in national and international collaboration papers. Numbers between parentheses correspond to researchers by affiliation.

\begin{tabular}{|c|c|c|c|c|c|}
\hline $\begin{array}{l}\text { Number of } \\
\text { institutions }\end{array}$ & \multicolumn{2}{|c|}{$\begin{array}{c}\text { National } \\
\text { Collaboration papers }\end{array}$} & \multicolumn{2}{|c|}{$\begin{array}{c}\text { International } \\
\text { Collaboration papers }\end{array}$} & Total \\
\hline 1 & \multicolumn{2}{|c|}{-} & \multicolumn{2}{|c|}{-} & 17 \\
\hline 2 & 25 & $\begin{array}{l}9 \times(1+1) \\
4 \times(2+1) \\
\end{array}$ & 55 & $\begin{array}{l}23 \times(1+1) \\
19 \times(2+1)\end{array}$ & 80 \\
\hline 3 & 9 & $5 \times(2+1+1)$ & 18 & $\begin{array}{l}7 \times(1+1+1) \\
4 \times(2+1+1)\end{array}$ & 27 \\
\hline$\geq 4$ & \multicolumn{2}{|c|}{0} & 8 & $2 \times(2+2+1+1)$ & 8 \\
\hline
\end{tabular}

The temporal evolution of pure domestic co-authorship is not significant because of the drastic decrease of papers with this type of collaboration after 2004. Also, researchers of the Faculty of Sciences of Marrakech showed the most intense national collaborative behavior as they co-authored papers with researchers from up to 11 institutions since 1992, especially from the neighboring (and in some sense daughter institution) Faculty of Sciences and Techniques of Marrakech (4 papers). The oldest institutions, the Faculty of Sciences of Rabat (papers since 1983) and the Institut Scientifique, a national research institute in Rabat, collaborated with 8 institutions.

\section{International Collaboration}

Several parameters were calculated from the 190 articles co-authored by Moroccan and foreign researchers (almost $75 \%$ of the total output).

The first is the percentage of Moroccan and foreign authors. Among the 1051 authors found (repetitions allowed), 503 are from Morocco (about $48 \%)$ and $548(52 \%)$ belong to other 31 countries.

In Morocco, the institutions which show the largest international collaboration are the Faculty of Sciences of Marrakech. The 52 internationally co-authored papers were mainly with researchers from France with 34 papers (80\%) and 75 co-authors (61.44\%), while the other co-authored papers were insignificant (collaboration with Spain only produced 3 papers and 11 coauthors).

By country, the largest number of co-authored papers and co-authors (repetitions allowed) belongs to France with 121 papers (63\%) and 258 researchers (47\% of foreign authors) as shown in Figure 6 and Table 4. Thus, this is followed by Spain with 30 papers (16\%) and 80 co-authors (14.7\%) and Italy with 14 papers and 36 co-authors $(6.6 \%)$. The other countries are shown in Figure 6. Only 14 papers were co-authored with African researchers and institutions. 


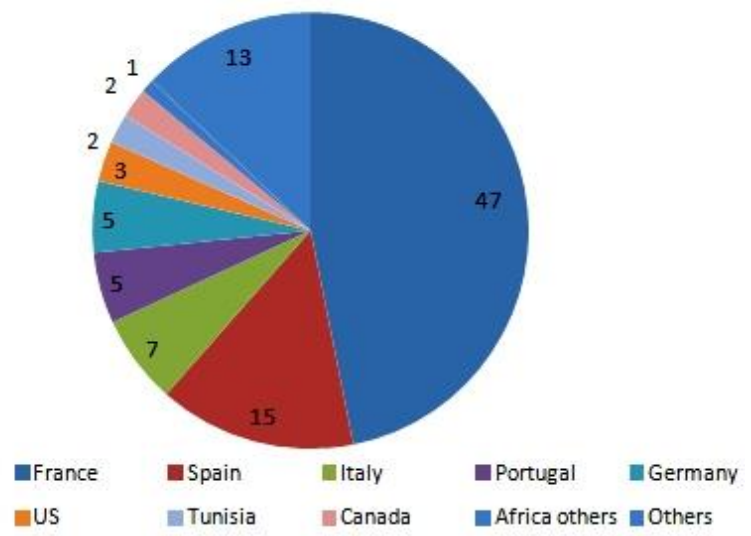

Figure 6. Percentage of foreign co-authors' affiliations collaborating with Moroccan researchers from 1984 to 2019 in articles of JAES

As previously indicated, the main output shown in Figure 7 was with the FS of Marrakech with 34 papers, followed by the FS El Jadida (21), FST Marrakech (18), FS Agadir (17), FS Rabat (15), FS Casablanca-Ain Chock (10), the ENS teachers formation institutions (10), and the Geological Service of the Ministry of Mines (10).

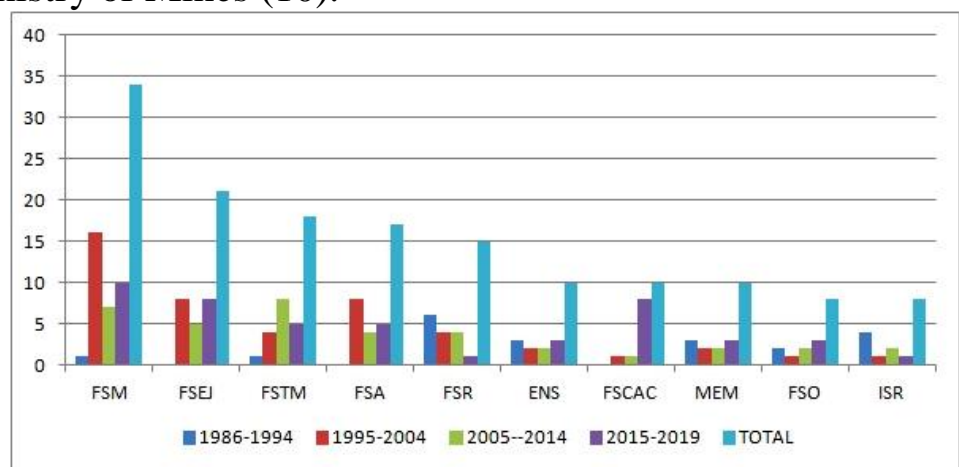

Figure 7. Evolution of the number of papers co-authored by French researchers with various Moroccan institutions from 1984 to 2019 in the JAES 
Table 4. Number of articles and French co-authors in the JAES from collaboration with Morocco

\begin{tabular}{lcccccccc}
\hline \multirow{2}{*}{ France } & $\mathbf{1 9 8 4 -}$ & $\mathbf{1 9 9 0 -}$ & $\mathbf{1 9 9 5 -}$ & $\mathbf{2 0 0 0 -}$ & $\mathbf{2 0 0 5 -}$ & $\mathbf{2 0 1 0 -}$ & $\mathbf{2 0 1 5 -}$ & \multirow{2}{*}{ Total } \\
& $\mathbf{1 9 8 9}$ & $\mathbf{1 9 9 4}$ & $\mathbf{1 9 9 9}$ & $\mathbf{2 0 0 4}$ & $\mathbf{2 0 0 9}$ & $\mathbf{2 0 1 4}$ & $\mathbf{2 0 1 9}$ & \\
\hline Articles & 6 & 11 & 13 & 28 & 13 & 16 & 34 & $\mathbf{1 2 1}$ \\
\hline Authors & 11 & 19 & 24 & 47 & 28 & 40 & 89 & $\mathbf{2 5 8}$ \\
\hline Auth/Pap & 1.83 & 1.72 & 1.84 & 1.68 & 2.15 & 2.5 & 2.61 & $\mathbf{2 . 1 3}$ \\
\hline
\end{tabular}

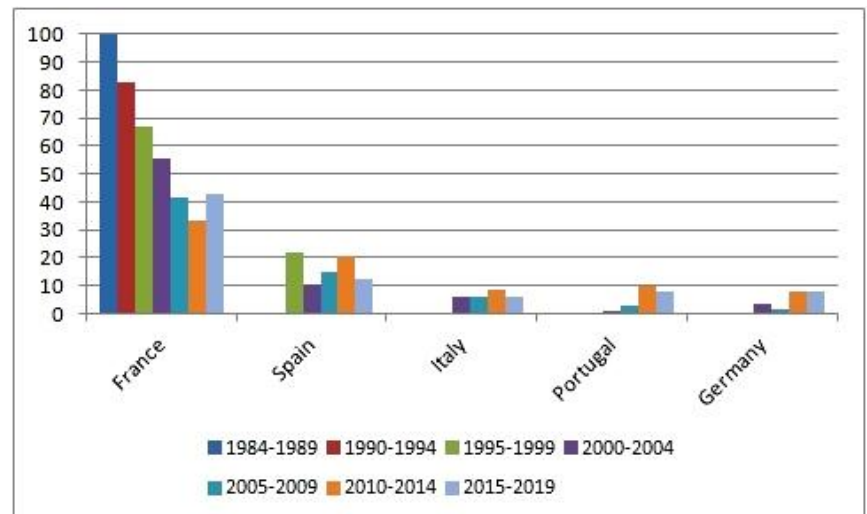

Figure 8. Evolution of the percentage of foreign co-authors collaborating with Moroccan researchers in articles of JAES from 1984 to June 2019

However, when the temporal evolution of collaboration is analyzed by 5-year periods (Figure 8), it can be observed that with respect to other foreign nationalities, the percentage of French co-authors decreased steadily from almost $100 \%$ in $1984-1989$ to $33 \%$ in $2010-2014$, recovering to $42 \%$ in 2015 2019. On the other hand, those of other countries increased before a slight decrease in the last 5 years mainly because of the larger increase of French coauthors.

\section{Interpretation and Discussion}

\subsection{Authorship and Research Collaboration}

It is important to point out that it is beyond the scope of this paper to discuss whether co-authorship reflects or not a full or partial collaboration (e.g., Laudel, 2002). Therefore, it is considered that co-authorship is fairly a good reflection of collaboration.

From the data exposed in Section 3, it appears that only 12 papers were single-authored in order to make the rule of collaboration and co-authorship. This was found by Kleiche-Dray (2007; her Table 4) who, from Thomson Scientific Data, stated that international collaborative share (\%) of astro- and geo-sciences in Moroccan papers was in the range 70-80\%. 
The most frequent number of co-authors was 4 (45 papers), a value which is in conformity with other studies on authorship in Earth sciences. For instance, Franceschet and Costantini (2010) found on the basis of 585 articles that the mean number of authors per paper in Earth sciences (Collaborative Level) was $C L=4.07$. This appears as a common feature in this domain, which requires a large effort in the field (e.g., mapping and sampling in mountainous areas), followed by long and expensive analytical procedures (preparation of thin slides and fossils, geochemical and isotope analyses). Thus, these are generally carried out and/or funded by two or more institutions.

The steady increase of the mean number of co-authors from 2 in the period 1984-1989 to 6 in the period 2010-2019 indicates that an increasing number of researchers were involved in bi- to multi-lateral collaboration projects. The largest number (19) of co-authors (Bensalah et al., 2013) was found for an international project involving several researchers from Morocco (5 institutions), Portugal (3), France (2), Italy (2), and Spain (1).

The fact that $67 \%$ of the first authors in international collaboration papers are Moroccan indicates that they are the main researchers of the collaborating team. In several cases, university teachers preparing their former State Thesis (Thèse d'Etat) and later $\mathrm{PhD}$ students occupy the first rank, certainly because they have carried out most of the technical/experimental task (fieldwork, sampling tasks and at least part of the analytical study generally in a foreign laboratory). Nonetheless, it is not certain that the PhD students were the co-authors who have prepared the manuscripts but may be the corresponding authors. As a result, the latter task was rather accomplished by an experienced researcher in order to shorten the delay of publication. When the first author is from a foreign country, it is either a $\mathrm{PhD}$ student or the main senior researcher of a bi- or multi-lateral project. Finally, when there is only one Moroccan researcher with a low rank in the authors' list, it generally corresponds to a research program led by a foreign laboratory, which includes a local researcher or administrator because of his knowledge of the field or/and his ability to facilitate contacts with scientific and administrative authorities.

\subsection{Evolution of Domestic Collaboration}

As exposed in Section 3.3.1., domestic collaboration between Moroccan universities and companies is relatively low because of the same shared problems. Therefore, much of this collaboration is individual and vertical, often between supervisors and their students who became teachers and staff members at the new faculties, administrations and companies.

There are a few publications in which there was also an apparent horizontal collaboration. For instance, several PhD students conducted studies of mining and hydrocarbon exploration which triggered collaboration between the university and the Moroccan offices and companies such as the Petroleum 
Office ONAREP (lately ONHYM-pôle hydrocarbures), Office Chérifien des Phosphates (OCP), MANAGEM, and ONHYM-pôle mines. Vertical collaboration may also be present when the former student is working in a company but still has papers with his former supervisor. Another example of real horizontal collaboration may be illustrated by the PNCG geological mapping program, conducted by researchers but managed by private offices, whose products are geological maps published by the Geological Service (not included in Scopus database).

Horizontal collaboration is also present when one co-author is outside the university but provides a useful database that cannot be exploited by his/her administration. This is current in geophysics and water science.

\subsection{Evolution of International Collaboration}

In the 1980s, collaborating institutions and authors were almostexclusively from France. Despite the increase of their numbers, the percentage with respect to authors from other countries decreased reaching only $33 \%$ in 2010-2014 before rising again to 42\%. The other co-authors of articles published in 1984-2019 belong to Spain, Italy, Portugal, Germany, the United States, Tunisia, and to 24 more countries. This evolution was also noted by Kleiche-Dray (2007; her Table 5) for the short period 2001-2004 (all disciplines), where the percentage of French partners fell from $71 \%$ to $62.7 \%$, while Spain and Germany increased their share.

This shift in collaborating countries can be explained by several factors:

i. By the early years of post-independence research in Morocco, the «Marocanization» period (1970s and especially the early 1980s), which corresponds to the replacement of French teachers by Moroccan ones, most young researchers were still attached to the French universities where they generally prepared their theses and published their work with their supervisor(s). Among the possible collaboration types (Laudel, 2002), this can be considered as a simple vertical collaboration. In addition, France was the only country which had cooperation agreements with Morocco (Actions Intégrées, CNRSCNRST) (Kleiche-Dray, 2007), which in most cases also involved a strong vertical collaboration and a weak horizontal one. Consequently, it is not surprising that most foreign co-authors (at least in this journal) were from France.

ii. Afterwards, probably because the Moroccan ministry of higher education and the CNRST signed new cooperation agreements with research institutions of other European countries, several senior Moroccan researchers started working with laboratories out of France, which often offered better technical and financial support than the 
French ones (e.g., CSIC, DFG, NSF). It can also be taken into consideration that several former supervisors of Moroccan researchers attained retirement age and their laboratories changed their personnel and often research policy (e.g., shift from structural to environmental geology).

iii. More recently, several projects, such as the European Union-funded projects for peri-Mediterranean countries (e.g., PHC-Maghreb, ScolaMAR), led to a large increase in the number of collaborating nations and teams, making the number of co-authors rise to more than 6 authors.

iv. It is also important to note that the shift of the journal language from French and English to English exclusively in the early 2000s was a major factor in determining the change in collaboration. Thus, it is required that the Moroccan senior researchers should make an additional effort to learn English writing to facilitate an easier communication process with English-speaking researchers (e.g., Spain, Portugal, and Germany) and to trigger new collaboration projects.

However, collaboration with French researchers and institutions is still important as shown by the high percentage of papers (80\%) co-authored with the most collaborative Moroccan university, the Faculty of Sciences of Marrakech, especially in tectonics, geochemistry, and metallogeny. One reason is that a large number of high-level researchers in France (head of laboratories and advisors to regional institutions), who are originally Moroccan, have studied in Morocco. Hence, they still have strong tights with their original universities, especially in the field of environmental geology and natural hazards.

It should be pointed out that, in conformity with the conclusions of Adams et al. (2014), collaboration with African countries through JAES is extremely low, with only 14 papers and 23 co-authors. The largest coauthorship was with Tunisia (6 papers and 11 co-authors), Egypt, and South Africa (3 papers and 5 co-authors each). Two other papers were co-authored with Nigeria and Côte d'Ivoire in the latter case by a former PhD student in Rabat. However, collaboration appears to be reflected through other journals which are not internationally indexed, especially the Notes et Mémoires du Service Géologique du Maroc, where South African geologists have published the descriptions of several geological maps elaborated in the context of the PNCG program.

In the case of Algeria, the absence of collaboration is obviously related to the political situation and the closure of the frontier, although several issues could be shared such as the seismic and tsunami hazards. It is also surprising 
that no collaboration exists with other countries of the Union du Maghreb Arabe (UMA) such as Libya (before the present-day conflict) and Mauritania, except for sporadic papers. It can be easily understood that Libyan researchers in geosciences are focalized on petroleum geology and may consequently have more fruitful collaboration with Egypt and Algeria.

\subsection{Impact on Moroccan Researchers and Laboratories}

It is clear that domestic and international collaboration have a positive impact on individual researchers and their laboratories, the most obvious being the increase of the number of publications (Franceschet \& Constantini, 2010). However, the fact that almost $70 \%$ of the papers published on Morocco in the JAES were exclusively co-authored by foreign researchers (European Union mainly) indicates little North-South collaboration and therefore no benefits for the national researchers in terms of knowledge and technological transfer.

Individual researchers benefit from the knowledge provided by the international programs, and also from the publication of papers in high-impact factor journals which in turn has a large impact on their career and advance. It is very difficult to determine the level of the researchers because their contributions to the research programs remain quite undefined although they are certainly a milestone in the field studies. When examining the researchers' output, the scientific commissions of Moroccan universities take into account the number of publications in Scopus-indexed journals and the authors' rank but his h- and g-indexes have been ignored to date, with the exception of the Hassan II Academy of Sciences and Techniques.

The impact on Moroccan PhD students' career is important as they benefit from high quality scientific and technological knowledge which may help them find a teaching/research position easily, although rarely in their original domain.

The impact on the Moroccan laboratories may be important from the output point of view. However, it is not obvious in terms of technological transfer, as most programs do not include acquisition of heavy scientific material such as analytical facilities for geophysical and geochemical studies. In addition, such heavy technology should need high-level operators for maintenance and hence a huge know-how transfer. Nonetheless, there are a few exceptions, such as the gift of 4 broadband seismographs by the European institutions to the Institut Scientifique of Rabat and permanent GPS stations offered by Portugal and the United States to the same institute and to the Faculty of Sciences of Marrakech. As stated in the previous section, French researchers of Moroccan origin contribute to transfer their know-how to their partners in Morocco. Although there is no technological transfer, they often receive colleagues and students for training. 
Due to the lower level of scientific research and technology of Moroccan institutions with respect to those of the collaborating countries, one major question is: does the collaboration correspond to a real horizontal collaboration? And if so, what is the degree of asymmetry?

Indeed, bibliometric research can provide us with some information depending on the number of Moroccan or other affiliations. The gathered coauthored papers were grouped into perfectly symmetric (50\% of Moroccan coauthors), sub-symmetric ( $40 \%$ to $49 \%$ of Moroccan or other affiliations), slightly asymmetric (33\%-39\%), asymmetric (25\%-32\%), highly asymmetric $(20 \%-25 \%)$, and extremely asymmetric $(<20 \%)$. The results show a good symmetry between Moroccan and foreign researchers for all categories (e.g., $1+3$ and $3+1)$ with the exception of the extremely high asymmetric coauthorships (e.g., $1+6$ to $1+10$ ), which are inclined toward foreign affiliations.

In the Earth science domains with reduced analytical tasks, such as structural geology or continental sedimentology, there appears some symmetry because the foreign partners may only contribute by their knowledge and a little simple software. In contrast, when the foreign partners contribute by high technological tasks (use of vessels, geochemical and isotope analyses, and seismic surveys), the collaboration becomes highly asymmetric as can be inferred from the publications where a small number of Moroccan researchers are involved with a low rank among the authors.

\section{Conclusion}

In this paper, the output of the Moroccan researchers in Earth sciences was studied through the example of the JAES, one of the most preferred journals by this community. The main results are:

1. A total of 703 Moroccan researchers participated in 253 articles, among which only 12 were single-author papers. Multi-authorship is the rule with a mode of 4 authors per paper for 45 articles.

2. The number of authors reached 1253 in all papers. When only international collaboration is considered, 1053 authors are found, among which about 503 (48\%) are from Morocco and $548(52 \%)$ belong to other 31 countries.

3. International collaboration, which was exclusively with French researchers and institutions until the 1990s, declined to $42 \%$ in the last years, while collaboration with other countries became more important because of the internationalization of research programs.

Despite the small database, this particular journal seems to perfectly reflect the trends in collaboration of Moroccan authors and institutions with foreign ones in geosciences. 


\section{Acknowledgements}

The author would like to express his gratitude to Profs Mimoun Harnafi (Institut Scientifique, Rabat), Abdellah Ammar (Faculty of Sciences, Rabat), and Nasrreddine Youbi (Faculty of Sciences, Marrakech) for the fruitful information on the international collaboration programs they are managing or have managed. Special thanks to Drs. Nirmal Kumar Bitchoo (Université des Mascareignes, Mauritius) and Sigit Tryono (Universitas Negeri, Indonesia) for their remarks and suggestions.

\section{References:}

1. Abramo, G., D'Angelo, C.A. \& Murgia, G. (2013). The collaboration behaviors of scientists in Italy: a field level analysis. Journal of Informetrics, 7, 442-454

2. Adams, J., Gurney, K., Hook, D. \& Leydersdorff, L. (2014). International collaboration clusters in Africa. Scientometrics, 98, 547556.

3. Bensalah, M. K., Youbi, N., Mata, J., et al. (2013). The JurassicCretaceous basaltic magmatism of the Oued El-Abid syncline (High Atlas, Morocco): physical volcanology, geochemistry and geodynamic implications. Journal of African Earth Sciences, 81, 60-81.

4. Bouabid, H. \& Martin, B.R. (2009). Evaluation of Moroccan research using a bibliometric based approach: investigation of the validity of the h-index'. Scientometrics, 78/2: 203-217.

5. Département de l'Enseignement Supérieur, de la Formation des Cadres et de la Recherche Scientifique (2006). Vision et stratégie de la recherche horizon 2025.

http://www.auf.org/media/IMG2/pdf/Rapport_Recherche_Scientifiqu e_Maroc-2.pdf

6. Franceschet, M. \& Costantini, A. (2010). The effect of scholar collaboration on impact and quality of academic papers. Journal of Informetrics, 4, 540-553.

7. Glänzel, W. \& Schubert, A. (2004). Analysing scientific networks through co-authorships. In Moed, H.F. et al. (Eds): Handbook of quantitative Science and technology research. Kluwer Academic Publishers, pp. 257-276.

8. Gomez, I., Fernandez, M.T. \& Sebastian, J. (1999). Analysis of the structure of international scientific cooperation networks through bibliometric indicators. Scientometrics, 44, 3, 441-457.

9. Hagedoorn, J., Link, A.N. \& Vonortas, N. (2000). Research partnerships. Research Policy, 29, 567-586.

10. Katz, J.S. \& Martin, B.R. (1997). What is research collaboration? Research Policy, 26, 1-18. 
11. Kleiche-Dray, M. (2007). La recherche scientifique au Maroc; rapport de synthèse. Institut de Recherche et Développement. http://www.estime.ird.fr/IMG/pdf/Estime_synthese_Maroc_v2.pdf. Accessed 10 July 2014

12. Laudel, G. (2002). What do we measure by co-authorship? Research Evaluation, 11, 1, 3-15.

13. Levitt, J.M. \& Thelwall, M. (2009). Citation levels and collaboration within library and information science. Journal of the American Society for Information Science and Technology, 60, 3, 434-442.

14. Leydersdorff, L. \& Wagner, C.S. (2008). International collaboration in science and the formation of a core group. Journal of Informetrics, 2, 317-325.

15. Medina, F. (2015). The output of researchers in Morocco compared to some North African countries from 1996 to 2012, and its relationship to governmental major decisions on higher education and scientific research. Scientometrics, DOI 10.1007/s11192-015-1701-8

16. Van Leeuwen, T. N. (2005). Strength and weakness of national science systems: A bibliometric analysis through cooperation patterns. Scientometrics, 79, 2, 389-408.

17. Waast, R. \& Kleiche-Dray, M. (2009). Evaluation of a national research system: Morocco. European Commission, Luxembourg: Office for Official Publications of the European Communities, series Capacity, 7, $164 \mathrm{p}$.

18. Zitt, M. \& Bassecoulard, E. (2004). Internationalisation in Science in the prism of bibliometric indicators. In Moed, H.F. et al. (Eds): Handbook of quantitative Science and technology research. Kluwer Academic Publishers, pp. 407-434. 


\section{Appendix: Abbreviations used}

CERN: Formerly Conseil Européen pour la Recherche Nucléaire, now European Organization for Nuclear Research

CNRS: Centre National de la Recherche Scientifique (France)

CNRST: Centre National de la Recherche Scientifique et Technique (Morocco)

CSIC: Consejo Superior de Investigacion Cientifica (Spain)

DESFCRS: Département de l'Enseignement Supérieur, de la Formation des Cadres et de la Recherche Scientifique

DFG: Deutsche Forschungsgemeinschaft (Germany)

IOC/ICG/NEAMTWS: International Oceanographic Commission/ International Coordination Group / North Eastern Atlantic and Mediterranean Tsunami Warning System

ISI: Institute of Scientific Information

JAES: Journal of African Earth Sciences

NSF: National Science Foundation (United States)

ONHYM: Office National des Hydrocarbures et des Mines (Morocco)

PARS: Programme d'Appui à la Recherche Scientifique (Morocco)

PROTARS : PROgramme Thématique d'Appui de la Recherche Scientifique (Morocco).

PHC: Partenariats Hubert Curien (France/Europe)

PNCG: Programme National de Cartographie Géologique (Morocco)

SCI: Science Citation Index

UATRS: Unités d'Appui Techniques à la Recherche Scientifique

WM: West Mediterranean seismological network 